\title{
El tratamiento sobre estereotipos de género en los dictámenes del Comité de Eliminación de la Discriminación contra la Mujer*
}

\author{
Judith Salgado Álvarez**
}

RESUMEN

Este artículo estudia dictámenes del Comité de Eliminación de la Discriminación contra la Mujer sobre comunicaciones individuales en los que se alega y/o se declara la violación del art. 5 a) de la CEDAW que establece la obligación de los Estados de modificar los patrones socioculturales de conducta de hombres y mujeres, con el fin de eliminar los prejuicios y las prácticas consuetudinarias basados en ideas de inferioridad y superioridad entre los sexos y de funciones estereotipadas entre hombres y mujeres. Da cuenta de los aportes y límites que encontramos en tales dictámenes respecto al tratamiento de estereotipos de género y su incidencia en la violencia y discriminación contra la mujer. Defiende la necesidad de poner atención a la identificación de estereotipos de género vinculados con la subordinación de la mujer para lograr superarlos. Para el efecto, los desarrollos interpretativos del Comité de la CEDAW expresados, entre otros, en sus dictámenes constituyen una fuente ineludible tanto para la elaboración de normativa y políticas públicas como para la administración de justicia.

Palabras Clave: estereotipos de género, Comité de Eliminación de la Discriminación contra la Mujer, discriminación y violencia contra la mujer.

\section{ABSTRACT}

This article analyses the adoption of views of individual communications submitted to the Committee on the Elimination of Discrimination Against Women, in which the complainers allege and/or it is declared the violation of art. 5 a) of the Convention on the Elimination of All Forms of Discrimination Against Women,

* $\quad$ Este artículo es una versión resumida del informe del proyecto de investigación "El tratamiento sobre estereotipos de género en los dictámenes del Comité de Eliminación de la Discriminación contra la Mujer”, financiado por el Fondo de Investigaciones para docentes contratadas de la Universidad Andina Simón Bolívar, Sede Ecuador.

** Docente de la Universidad Andina Simón Bolívar, Sede Ecuador, y de la Pontificia Universidad Católica del Ecuador. 
which determines the obligation of State Parties to modify the social and cultural patterns of conduct of men and women, with a view to achieving the elimination of prejudices and customary and all other practices which are based on the idea of the inferiority or the superiority of either of the sexes or on stereotyped roles for men and women. It points out the limits and contributions that we find out in the Committees treatment on gender stereotypes and its incidence on violence and discrimination against women. It defends the need to pay accurate attention to the identification of gender stereotypes linked with women's subordination, to overcoming them. For this purpose, the CEDAW interpretative developments, expressed, among others, in its adoption of views constitute an unavoidable source both for the approval of legislation and public policies as for justice administration.

KeYwords: gender stereotypes, Committee on the Elimination of Discrimination Against Women, violence and discrimination against women.

\section{INTRODUCCIÓN}

$\mathrm{U}$

n referente fundamental de la lucha de organizaciones feministas y de mujeres a nivel mundial es la Convención de Eliminación de Todas las Formas de Discriminación contra la Mujer, conocida como CEDAW, por sus siglas en inglés. ${ }^{1}$

Alda Facio se refiere a este tratado internacional como la Carta Magna de las mujeres, ${ }^{2}$ y afirma que se trata del primer instrumento internacional de derechos humanos con perspectiva de género. Uno de los aportes que resalta es que este instrumento internacional reconoce el papel de la cultura y las tradiciones en el mantenimiento de la discriminación contra las mujeres, y obliga a los Estados a eliminar estereotipos en los roles de hombres y mujeres. En efecto, el art. 5 a) de la CEDAW dispone que:

Los Estados Partes tomarán todas las medidas apropiadas para:

a) Modificar los patrones socioculturales de conducta de hombres y mujeres con miras a alcanzar la eliminación de los prejuicios y de las prácticas consuetudinarias y de cualquier otra índole que estén basados en la idea de superioridad e inferioridad de cualquiera de los sexos o en funciones estereotipadas de hombres y mujeres.

1. Adoptada por la Asamblea General de las Naciones Unidas el 18 de diciembre de 1979, entró en vigor el 3 de septiembre de 1981. Fue ratificada por Ecuador el 9 de noviembre de 1981.

2. Alda Facio, "La Carta Magna de todas las mujeres", en Ramiro Ávila, Judith Salgado y Lola Valladares, comp., El género en el derecho. Ensayos críticos (Quito: Ministerio de Justicia y Derechos Humanos/ UNIFEM/Alto Comisionado de las Naciones Unidas para los Derechos Humanos, 2009), 541-58. 
La CEDAW incluye el establecimiento de un Comité para la Eliminación de la Discriminación contra la Mujer (el Comité) encargado de examinar los progresos realizados por los Estados Partes en la aplicación de la CEDAW a través de la revisión de informes estatales periódicos y la emisión de sus Observaciones Finales al respecto.

Con la entrada en vigencia del Protocolo Facultativo de la CEDAW, ${ }^{3}$ los Estados Partes que lo hayan ratificado reconocen también la competencia del Comité para recibir y considerar las comunicaciones presentadas por personas o grupos de personas que se hallen bajo su jurisdicción y que aleguen ser víctimas de una violación a cualquiera de los derechos enunciados en la CEDAW.

El Comité ha producido desde el año 2005 un acervo jurisprudencial significativo a través de los dictámenes relativos a las comunicaciones individuales, ${ }^{4}$ que contribuye tanto al esclarecimiento de los contenidos de los derechos reconocidos en la CEDAW, así como a las obligaciones de los estados en cuanto a su cumplimiento y la responsabilidad por su incumplimiento.

Los desarrollos teóricos de Rebecca Cook y Simone Cusack sobre estereotipos de género son un referente importante de este trabajo de investigación. Estas autoras definen el término estereotipo como "una visión generalizada o una preconcepción sobre los atributos y características de los miembros de un grupo en particular o sobre los roles que tales miembros deben cumplir". ${ }^{5}$ Es importante resaltar que, para calificar una generalización como un estereotipo, no importa si dichos atributos o roles son comunes o no a quienes integran un determinado grupo. El elemento clave es que a partir de esta presunción se cree que una persona, por el mero hecho de pertenecer a dicho grupo, actuará de conformidad con tal visión generalizada. ${ }^{6}$

Siguiendo a estas autoras, en este trabajo, se entienden los estereotipos de género como la construcción social y cultural de hombres y mujeres, en razón de sus diferentes funciones físicas, biológicas, sexuales y sociales. En otras palabras, hacen referencia a un grupo estructurado de creencias sobre los atributos, características de la personalidad, comportamientos, roles, características físicas y apariencia, ocupaciones o presunciones sobre la orientación sexual de hombres y mujeres. ${ }^{7}$ Rebecca Cook y Simone Cusack desarrollan cuatro clases de estereotipos de género, a saber:

3. Aprobado por la Asamblea General de las Naciones Unidas el 6 de octubre de 1999, entró en vigencia el 22 de diciembre de 2000. Fue ratificado por Ecuador el 5 de febrero de 2002.

4. De acuerdo con la información que consta en la página web de la Oficina de las Naciones Unidas del Alto Comisionado para los Derechos Humanos el Comité de la CEDAW ha emitido un total de 41 dictámenes hasta abril de 2015. Cfr. «www.ohchr.org〉.

5. Rebecca Cook y Simone Cusack, Estereotipos de género. Perspectivas Legales Transnacionales (Bogotá: Profamilia, 2010), 11.

6. Ibíd., 11.

7. Ibíd., 23. 
1. Los estereotipos de sexo que describen "una noción generalizada o preconcepción que concierne a los atributos y características de naturaleza física o biológica que poseen los hombres y las mujeres". ${ }^{8}$

2. Los estereotipos sexuales que dotan a los hombres y a las mujeres de características y cualidades sexuales específicas que juegan un papel en la atracción y el deseo sexual, la iniciación sexual y las relaciones sexuales, la intimidad, posesión y violencia sexuales, el sexo como transacción, la cosificación y explotación sexual. Comprende la forma en que las sociedades prescriben los atributos sexuales de las mujeres tratándolas como propiedad sexual de los hombres y condenándolas por mostrar comportamientos promiscuos, a la vez que los hombres no son responsabilizados por los mismos comportamientos. Los estereotipos sexuales han sido usados para regular la sexualidad de las mujeres y justificar y proteger el poder masculino en función de su gratificación sexual. Los estereotipos sexuales demarcan las formas aceptables de sexualidad masculina y femenina, privilegiando la heterosexualidad sobre la homosexualidad. ${ }^{9}$

3. Los estereotipos sobre roles sexuales describen una noción generalizada sobre los roles o comportamientos que se consideran apropiados para hombres y mujeres. ${ }^{10}$

4. Los estereotipos compuestos que son aquellos en los que el género se intersecta con otros rasgos como la edad, la raza o etnia, la discapacidad, orientación sexual, clase, estatus como nacional o migrante, etc. ${ }^{11}$

Un punto fundamental es que los estereotipos, en general, y los de género, en particular, se encuentran muy arraigados en nuestro inconsciente, los aceptamos sin ninguna crítica, como una manera inevitable de entender la vida. Esto implica que nuestros encuentros cotidianos con los estereotipos son, frecuentemente, invisibles y no los detectamos: ${ }^{12}$

En los casos en que un estereotipo opera sin ser detectado y es reafirmado por el statu quo, la jerarquía de género dominante, o más generalmente, por las jerarquías de poder social o económico, una medida necesaria para su eliminación es tomar conciencia de su existencia e identificar cómo perjudica a las mujeres. Esto equivale a decir que hacer un diagnóstico de los estereotipos como causantes de un daño social, es una precondición para determinar su tratamiento. El análisis legal y de derechos humanos puede ser instrumental en la formulación del diagnóstico sobre un estereotipo, el cual es un prerrequisito necesario para su eliminación. ${ }^{13}$

\footnotetext{
8. Ibíd., 29.

9. Ibíd., 31-2.

10. Ibíd., 32.

11. Ibíd., 34.

12. Ibíd., 37.

13. Ibíd., 43.
} 
De otra parte, no se puede perder de vista la carga de legitimidad vinculada con el derecho, tal como advierten Cook y Cusack: "cuando un Estado aplica, ejecuta o perpetúa un estereotipo de género en sus leyes, políticas públicas o prácticas, lo institucionaliza, dándole la fuerza y autoridad del derecho y la costumbre. El ordenamiento jurídico, como una institución estatal, condona su aplicación, ejecución y perpetuación y por lo tanto genera una atmósfera de legitimidad y normalidad”. ${ }^{14}$

Por lo tanto, resulta muy importante develar la persistencia de estereotipos de género y su incidencia en la limitación o anulación del reconocimiento, ejercicio y goce de los derechos humanos de las mujeres. Así, la pregunta que busca responder este artículo es ¿qué aportes y límites se encuentra en el desarrollo jurisprudencial del Comité de la CEDAW, expresado en sus dictámenes respecto de comunicaciones individuales, con relación a los estereotipos de género y su incidencia en la discriminación y violencia contra las mujeres?

\section{ANÁLISIS DE LA JURISPRUDENCIA DEL COMITÉ DE LA CEDAW SOBRE ESTEREOTIPOS DE GÉNERO}

Esta investigación se centra en el análisis de doce (12) dictámenes emitidos por el Comité entre los años 2005 a 2015. El principal criterio para la selección de estos dictámenes es que incluyen la alegación y/o determinación de la violación del art. 5 a) de la CEDAW, relacionado con la obligación de los Estados de eliminar estereotipos basados en ideas de inferioridad y superioridad entre hombres y mujeres.

De estos doce (12) dictámenes, se encuentra dos (2) comunicaciones individuales contra Austria; dos (2) contra Bulgaria; dos (2) contra Filipinas; y una (1) por cada uno de los siguientes Estados: Belarús, España, Hungría, Perú, República Unida de Tanzania y Turquía. La mitad se relacionan con casos de violencia contra la mujer en el ámbito familiar, concretamente en la relación de pareja. En tres de estos casos se llega a la violación del derecho a la vida, otros tres casos tienen que ver con violencia sexual, en dos de ellos se trata de la violación cometida por personas conocidas (vecino y jefe), y un caso de acoso sexual en un centro de detención estatal. Los últimos tres últimos casos tienen que ver con discriminación en el reconocimiento y ejercicio de derechos económicos, sociales y culturales, concretamente: derecho a la salud, al trabajo y a la propiedad.

Otro elemento común de estos casos, es que en todos ellos el Comité encuentra que el Estado ha sido responsable de la violación de derechos reconocidos en la CEDAW.

14. Ibíd., 42. 
No obstante, no en todos ellos, aunque sí en un número muy significativo (diez de doce), declara la violación del art. 5 a) relacionado con los estereotipos de género.

\section{VIOLENCIA CONTRA LA MUJER EN EL ÁMBITO FAMILIAR}

Dentro de los dictámenes del Comité relacionados con violencia doméstica que incluyen la violación del derecho a la vida (de las mujeres por parte de sus maridos, o de la hija por parte de su padre), encontramos los siguientes casos: Descendientes de Fatma Yildirim contra Austria, Descendientes de Sahide Guekce contra Austria y González contra España. ${ }^{15}$

Los dos casos seguidos en contra de Austria tienen muchas similitudes. ${ }^{16}$ Las víctimas son mujeres de nacionalidad austríaca y origen turco que vivieron historias de violencia por parte de sus maridos. Ambas fueron amenazadas varias veces de muerte, presentaron denuncias a la policía, obtuvieron órdenes de restricción de acercamiento que fueron varias veces incumplidas, sus maridos nunca fueron detenidos y terminaron siendo asesinadas por sus parejas.

Es importante incluir lo manifestado por el Comité en cuanto al hecho de que no se haya detenido en ninguna ocasión al agresor:

Aunque el Estado Parte sostiene con razón que es necesario en cada caso determinar si la detención constituiría una injerencia desproporcionada en los derechos básicos y las libertades fundamentales de un autor de actos de violencia en el hogar, como el derecho a la libertad de circulación y a un juicio imparcial, el Comité opina [...] que los derechos del agresor no pueden estar por encima de los derechos humanos de las mujeres a la vida y a la integridad física y mental. En el presente caso, el Comité considera que el comportamiento (amenazas, intimidación y golpes) de Mustafa Goekce transponía un alto umbral de violencia del cual tenía conciencia el fiscal y que, en consecuencia, el fiscal no debía haber denegado las solicitudes de la policía de detener a Mustafa Goekce $[. ..] .{ }^{17}$

15. Comunicación No. 47/2012. Ángela González Carreño contra España. Dictamen del Comité de Eliminación de la Discriminación contra la Mujer de 16 de julio de 2014.

16. Comunicación No. 6/2005. Hijos de Fatma Yildirim contra Austria. Dictamen del Comité de Eliminación de la Discriminación contra la Mujer de 6 de agosto de 2006 y Comunicación No. 5/2005. Descendientes de Sahide Goekce contra Austria. Dictamen del Comité de Eliminación de la Discriminación contra la Mujer de 6 de agosto de 2006.

17. Comunicación No. 5/2005. Descendientes de Sahide Goekce contra Austria. Dictamen del Comité de Eliminación de la Discriminación contra la Mujer de 6 de agosto de 2006, párrafo 12.1.5. En similar sentido ver Comunicación No. 6/2005. Hijos de Fatma Yildirim contra Austria. Dictamen del Comité de Eliminación de la Discriminación contra la Mujer de 6 de agosto de 2006, párrafo 12.1.5 y Comunicación No. 2/2003. 
También en los dos casos los autores alegan la violación del art. 5 de la CEDAW afirmando que el asesinato constituye:

Un ejemplo trágico de la falta de seriedad reinante con que se toman los casos de violencia contra la mujer, tanto por la población en general como por las autoridades austríacas. El sistema de justicia penal, especialmente los fiscales y los jueces, consideran la cuestión un problema social o doméstico, un delito menor o una infracción que ocurre en determinadas clases sociales. No aplican la legislación penal a ese tipo de violencia porque no se toman en serio el peligro que representa y consideran los miedos y las preocupaciones de las mujeres con falta de seriedad. ${ }^{18}$

El Comité no declara en ninguno de los dos casos la violación del art. 5. En un párrafo general, y sin una adecuada motivación, descarta tal posibilidad. ${ }^{19}$ Ciertamente, habría sido una buena oportunidad para que el Comité desarrollara la relación entre un estereotipo o creencia generalizada que devalúa la palabra de una mujer víctima de violencia en el ámbito familiar. En los dos casos es claro que, a pesar de las evidencias de violencia en el ámbito familiar, la respuesta institucional no tuvo en cuenta la seriedad del riesgo que las víctimas estaban corriendo, aunque en varias ocasiones pusieron en conocimiento de las autoridades estatales esta situación.

Se puede decir que los dos casos evidencian androcentrismo en tanto la experiencia masculina se percibe como central, como la única relevante mientras que al mismo tiempo se invisibiliza o devalúa la experiencia femenina. ${ }^{20}$ En efecto, pesa mucho más en la decisión de la Fiscalía el proteger el derecho a la libertad del acusado, a pesar de la violación de derecho a la integridad personal de las víctimas y las evidencias de amenazas al derecho a la vida que finalmente se concretan.

Teniendo en cuenta que las dos mujeres eran de origen turco cabría preguntarse si en el caso también operaron estereotipos compuestos en los que, tanto su género como su origen nacional, se combinaron para configurar una mayor subordinación no solo frente al agresor sino frente a las autoridades austríacas. No se cuenta con suficiente información para afirmar que así fue, pero queda ciertamente la duda.

En el caso González contra España, la autora fue víctima de violencia física y psicológica por parte de su marido durante su matrimonio y cuando se separó. La

18. Comunicación No. 5/2005. Descendientes de Sahide Goekce contra Austria, párrafo 3.6. En el caso de Fatma Yildirim se repite casi igual el texto citado. Ver párrafo 3.6.

19. Comunicación No. 5/2005. Descendientes de Sahide Goekce contra Austria, párrafo 12.2. En el caso de Fatma Yildirim se repite casi igual el texto citado. Ver párrafo 12.2.

20. Alda Facio, “Metodología para el análisis de género del fenómeno legal”, en Ramiro Ávila, Judith Salgado y Lola Valladares, comp., El género en el derecho. Ensayos críticos (Quito: Ministerio de Justicia y Derechos Humanos/UNIFEM/Alto Comisionado de las Naciones Unidas para los Derechos Humanos, 2009), 203. 
mayor parte de estos episodios de violencia se dieron delante de su hija en común. Entre 1999 y 2001 interpuso más de 30 denuncias solicitando órdenes de alejamiento respecto de ella y su hija. Inicialmente las autoridades establecieron visitas del padre vigiladas por el servicio social; posteriormente el padre solo debía recoger y entregar a la niña en dichos servicios. La madre se opuso a que las visitas no fueran vigiladas, sin embargo, sus pedidos no tuvieron acogida. El padre de la niña no cumplió con el pago de alimentos a favor de su hija por tres años. La autora solicitó ante los tribunales que se le otorgara el uso de la vivienda; el día de la audiencia su exmarido le amenazó con quitarle lo que más quería. El 24 de abril de 2003 en uno de los días de visita mató a su hija y se suicidó.

Con relación a cómo los estereotipos de género incidieron en la violación de sus derechos y los de su hija, la autora afirmó:

Que la existencia de prejuicios por parte de las autoridades se manifestó en la incapacidad de estas de apreciar correctamente la gravedad de la situación a la que ella y su hija se enfrentaban y su sufrimiento por la situación de la niña. Además, no se realizó una investigación de las consecuencias que tenía para la niña vivir en un ambiente de violencia y su condición de víctima directa e indirecta de esa violencia. En lugar de ello, las autoridades encargadas de otorgar protección privilegiaron el estereotipo de que cualquier padre, incluso el más abusador, debe gozar de derechos de visita y de que siempre es mejor para un niño ser educado por su padre y su madre; ello sin realmente valorar los derechos de la menor e ignorando que esta había manifestado tener miedo de su padre y rechazaba el contacto. [...]. Con base en estereotipos, el derecho de visita fue contemplado meramente como un derecho del padre y no como un derecho igualmente de la menor. El mejor interés de la niña hubiera requerido si no suprimir las visitas, al menos limitarlas a visitas vigiladas y cortas. ${ }^{21}$

\section{El Comité sostuvo que:}

Durante el tiempo en que se aplicó el régimen de visitas establecido judicialmente tanto las autoridades judiciales como los servicios sociales y los expertos psicológicos tuvieron como principal objetivo normalizar las relaciones entre padre e hija, a pesar de las reservas emitidas por estos dos servicios sobre el comportamiento de F.R.C. Las decisiones pertinentes no traslucen un interés por parte de esas autoridades de evaluar en todos sus aspectos los beneficios o perjuicios para la menor del régimen impuesto. También se observa que la decisión mediante la cual se pasó a un régimen de visitas no vigiladas fue adoptada sin previa audición de la autora y su hija, y que el continuo impago por parte de F.R.C. de la pensión de alimentos no fue tenido en consideración en este marco. Todos estos elementos reflejan un patrón de actuación que obedece a una concepción estereotipada del derecho de

21. Comunicación No. 47/2012. Ángela González Carreño contra España, párrafos 3.8-3.11. 
visita basado en la igualdad formal que, en el presente caso, otorgó claras ventajas al padre a pesar de su conducta abusiva y minimizó la situación de madre e hija como víctimas de violencia, colocándoles en una situación de vulnerabilidad. A este respecto, el Comité recuerda que en asuntos relativos a la custodia de los hijos y los derechos de visita el interés superior del niño debe ser una consideración esencial, y que cuando las autoridades nacionales adoptan decisiones al respecto deben tomar en cuenta la existencia de un contexto de violencia doméstica. ${ }^{22}$

En este caso, el Comité determina la existencia de un estereotipo respecto del derecho a la visita con base en la igualdad formal, que descuida un análisis prolijo del interés superior de la niña para el ejercicio concreto de dicho derecho, y que deja en una situación de vulnerabilidad tanto a la niña como a la madre por el contexto de violencia doméstica que no cobra suficiente peso en las decisiones de las autoridades nacionales. Es importante tener en cuenta la importancia del análisis del contexto y de cada caso en particular como elemento indispensable para ir más allá de la igualdad formal, y avanzar hacia una igualdad sustancial.

Un asunto que aparece en los hechos del caso, pero que no es retomado por el Comité, es que los servicios sociales que intervinieron daban cuenta de que, durante el tiempo de las visitas vigiladas, el padre hacía preguntas a su hija respecto de la madre y de su nueva relación de pareja. La utilización por parte del padre a su hija como una suerte de informante de la vida afectiva de su madre muestra en este caso cómo el derecho de visita es desvirtuado para convertirse en un dispositivo de control y vigilancia a la expareja. El caso muestra en extremis la objetivación de la niña, su asesinato es el medio que tiene como finalidad causar daño a la expareja al "quitarle lo que más quiere”.

Es posible relacionar esta actitud controladora del exmarido con los estereotipos sexuales que miran a la mujer como una propiedad del hombre sobre la cual es necesario ejercer vigilancia, control y dominio. Pero, adicionalmente, opera un estereotipo compuesto en el caso de la niña, quien fue en principio víctima indirecta de la violencia ejercida por su padre en contra de su madre, luego mientras estuvieron separados sufrió violencia psicológica al ser utilizada como mecanismo de control de su madre. Su edad en este caso fue un factor que agudizó su victimización pues su opinión no fue tenida en cuenta en las decisiones sobre el régimen de visitas con su progenitor. Finalmente, su vida fue arrebatada por su propio padre con el fin de dañar y castigar a la madre.

Siguiendo con dictámenes del Comité de la CEDAW relacionados con la violencia contra las mujeres en el ámbito familiar, y concretamente en la relación de pareja,

22. Ibíd., párrafos 9.4 y 9.7. 
se encuentran los casos A.T. contra Hungría, ${ }^{23}$ Komova ${ }^{24}$ contra Bulgaria, y Jallow contra Bulgaria. ${ }^{25}$

En estos tres casos las víctimas sufrieron violencia física, psicológica y económica por parte de sus maridos o convivientes, sin recibir una adecuada protección por parte de los Estados.

Respecto a la relación entre estereotipos de género y la violación de sus derechos se desarrollan los siguientes argumentos en el caso A.T. contra Hungría:

El Comité ha afirmado en muchas ocasiones que las actitudes tradicionales según las cuales se considera a la mujer como subordinada al hombre contribuyen a la violencia contra ella. [...] los hechos relatados en la comunicación revelan aspectos de las relaciones entre los sexos y actitudes hacia las mujeres que el Comité reconoció en relación con el país en conjunto. Durante cuatro años y hasta hoy, la autora se ha sentido amenazada por su ex pareja de hecho, padre de sus dos hijos. La autora ha sufrido lesiones causadas por el mismo hombre, es decir su ex pareja de hecho. La autora no ha conseguido, mediante ningún procedimiento civil o penal, que L. F. se mantenga alejado, temporal o permanentemente, del apartamento en que ella y sus hijos han seguido viviendo. La autora no podría haber solicitado una orden de alejamiento o de protección, porque tal cosa no es posible hoy en el Estado parte. No ha podido acudir a un centro de acogida porque no hay ninguno equipado para aceptarla junto con sus hijos, uno de los cuales padece una discapacidad grave. ${ }^{26}$

El estereotipo de roles sexuales que sostiene que dentro de una relación de pareja los hombres deben mandar/dominar y que las mujeres deben obedecer/subordinarse se ve reforzado a través de las instancias estatales que, al no brindar una protección adecuada a la mujer víctima de violencia por parte de su pareja, reafirman esa relación de dominación/subordinación y contribuyen así a la persistencia de la violencia y discriminación contra la mujer.

En el caso Komova contra Bulgaria, el Comité de la CEDAW insistió en que:

La concepción tradicional de que las mujeres están supeditadas a los hombres favorece la violencia contra ellas. [...] el Comité destaca que los estereotipos afectan el derecho de la mujer a un proceso judicial imparcial que la judicatura debe tener cuidado de no crear estándares inflexibles sobre la base de nociones preconcebidas de qué es lo que constituye

23. Comunicación No. 2/2003, A.T. contra Hungría. Dictamen del Comité de Eliminación de la Discriminación contra la Mujer de 26 de enero de 2005.

24. Comunicación No. 20/2008. Violeta Komova contra Bulgaria. Dictamen del Comité de Eliminación de la Discriminación contra la Mujer de 25 de julio de 2011.

25. Comunicación No. 31/2011. Isatou Jallow contra Bulgaria. Dictamen del Comité de Eliminación de la Discriminación contra la Mujer de 23 de julio de 2012.

26. Comunicación No. 2/2003, A.T. contra Hungría, párrafo 9.4. 
violencia doméstica o violencia por razón de género. [...] El Comité considera que la interpretación del Tribunal de Distrito y del Tribunal Regional de Plovdiv y la justificación del período de un mes dentro del cual la víctima debe solicitar una orden de protección (artículo 10, párrafo 1 de la Ley de Protección contra la Violencia en el Hogar) es que se procura proporcionar intervenciones urgentes del tribunal, y no vigilar la cohabitación de la pareja, carece de sensibilidad de género puesto que refleja la noción preconcebida de que la violencia doméstica es en gran medida una cuestión privada e incumbe a una esfera en que, en principio, el Estado no debe ejercer control. ${ }^{27}$

Este razonamiento del Comité pone en evidencia una de las ideas estereotipadas más frecuentes con relación a la violencia contra la mujer en el ámbito familiar, y es que se trata de un asunto que no incumbe sino excepcionalmente al Estado. En el trasfondo de esta idea estereotipada se asume que los espacios privados como la familia o las relaciones de pareja no están atravesados por relaciones de poder, sino que son los espacios del ejercicio de la libertad e intimidad que no deben ser perturbados por el Estado. Esta es sin duda una ficción ideológica más. ${ }^{28}$ Tal como lo demuestra Carole Pateman en su crítica a la dicotomía público/privado, “el supuesto liberal de que la autoridad del Estado se detiene en el umbral de la casa ha significado la desprotección a la mujer”. ${ }^{29}$

Resulta pertinente en este punto tener en cuenta que las ideas estereotipadas producen como consecuencia, por un lado, la justificación de actitudes y creencias pensando que son comunes, normales y correctas, y, por otro lado, que las personas estereotipadas negativamente tendrán menos oportunidades y la sociedad considerará que esto es culpa de ellas y por lo mismo sufrirán discriminación. ${ }^{30}$

Siguiendo con el caso Komova contra Bulgaria, el Comité sostuvo que:

La exclusiva concentración de los tribunales de Plovdiv en la violencia física y en la amenaza inmediata a la vida o la salud de la víctima, refleja un concepto estereotipado y excesivamente estrecho de qué es lo que constituye violencia doméstica. Esa interpretación estereotipada de la violencia doméstica se refleja, por ejemplo, en el razonamiento del Tribunal Regional de Plovdiv de que “cuando alguien golpea a otra persona, es posible ejercer

27. Comunicación No. 20/2008. Violeta Komova contra Bulgaria, párrafos 9.11 y 9.12.

28. Judith Salgado Álvarez, Manual de formación en género y derechos humanos (Quito: Universidad Andina Simón Bolívar/Corporación Editora Nacional, 2013), 98.

29. Carole Pateman, "Críticas feministas a la dicotomía público/privado, en Ramiro Ávila, Judith Salgado y Lola Valladares, comps., El género en el derecho. Ensayos críticos (Quito: Ministerio de Justicia y Derechos Humanos/UNIFEM/Alto Comisionado de las Naciones Unidas para los Derechos Humanos, 2009), 60.

30. M. Micaela Bazzano, “Estereotipos de género en la niñez. Una mirada desde los derechos humanos”, en Ana María Goetschel, coord., Perspectivas de la educación en América Latina (Quito: FLACSO/Ministerio de Cultura del Ecuador, 2009), 198. 
violencia pero solamente tras sobrepasar algunos límites de maltrato y en este caso las declaraciones de V. K. no aclaran de qué manera exactamente ella fue golpeada en la fecha indicada en el procedimiento, ni tampoco de qué manera quedó afectada su inviolabilidad”. Los estereotipos tradicionales del papel de la mujer en el matrimonio también pueden encontrarse en la sentencia de divorcio de fecha 8 de mayo de 2009 dictada por el Tribunal de Distrito de Plovdiv que menciona la utilización por la autora de "lenguaje insolente" al dirigirse a su esposo y le ordena usar su nombre de soltera tras la disolución del matrimonio. El rechazo por los tribunales de Plovdiv del pedido de obtener una orden de protección permanente contra el esposo de la autora se basó en nociones estereotipadas, preconcebidas y, por lo tanto, discriminatorias, de lo que constituye la violencia doméstica. ${ }^{31}$

Se aprecia en esta cita de qué manera el Comité devela una concepción estereotipada de la violencia doméstica reflejada en las afirmaciones de ciertos tribunales búlgaros que muestran una tolerancia de los golpes, que, en su visión, no constituyen violencia sino cuando exceden algunos límites del maltrato.

De otra parte, también se evidencian estereotipos de roles sexuales en la sentencia de divorcio. Implícitamente exigen a la mujer casada un comportamiento delicado, amable, prudente, moderado ${ }^{32}$ (aunque haya sufrido diversas formas de violencia) en contraposición con un comportamiento considerado reprochable como es el "lenguaje insolente” que sería inapropiado para una mujer. Este estereotipo guarda estrecha relación con una de las manifestaciones de sexismo como es el deber ser de cada sexo que “consiste en partir de que hay conductas o características humanas que son más apropiadas para un sexo que para el otro”. ${ }^{33}$

Sorprende además el doble parámetro. Por un lado, la tolerancia y flexibilidad para entender lo que puede ser calificado como violencia cuando son golpes proferidos por el marido a la mujer, y, por otro, la severidad para censurar un lenguaje "insolente" por parte de la mujer hacia su cónyuge. En el primer caso podríamos concluir que, desde la perspectiva del tribunal que conoció el caso de violencia contra la mujer, existe un nivel de violencia en las relaciones de pareja que sería admisible siempre que no sobrepase ciertos límites, que las mujeres deben soportar. Mientras que en el segundo caso un lenguaje “insolente” de la esposa contra su esposo resultaría siempre inaceptable.

En el caso Jallow contra Bulgaria el Comité reiteró que la concepción tradicional de que las mujeres están supeditadas a los hombres favorece la violencia contra ellas:

31. Comunicación No. 20/2008. Violeta Komova contra Bulgaria, párrafo 9.12.

32. Todos estos adjetivos son antónimos del adjetivo insolente.

33. Facio, “Metodología para el análisis de género del fenómeno legal”, 209. 
Respecto al caso que el Comité tiene ante sí, observa que al emitir una orden de protección de emergencia y adoptar otras decisiones, las autoridades del Estado parte se basaron en la declaración y acciones del marido, pese a ser conscientes de la posición vulnerable de la autora y su dependencia de él. El Comité observa también que las autoridades basaron sus actividades en la idea estereotipada de que el marido era superior y el único cuyas opiniones debían tenerse en cuenta, y no consideró que la violencia doméstica afecta proporcionalmente a muchas más mujeres que hombres. El Comité observa también que la autora fue separada de su hija durante un período de casi ocho meses, durante el cual no recibió ninguna información sobre los cuidados que estaba recibiendo su hija ni se le otorgaron derechos de visita. En tales circunstancias, el Comité considera que tanto la autora como su hija fueron víctimas de discriminación por motivo de género, ya que el Estado parte no protegió la igualdad de derechos de la autora en el matrimonio y como madre ni consideró que los intereses de su hija eran lo más importante. [...] la orden de protección de emergencia que separó a la autora de su hija se emitió sin considerar los anteriores incidentes de violencia doméstica ni la afirmación de la autora de que en realidad su hija y ella eran las que necesitaban protección contra la violencia doméstica [...]. ${ }^{34}$

Este caso devela otro estereotipo de género frecuente, y es aquel en que la palabra del hombre es valorada mientras la palabra de la mujer es devaluada. Se presta credibilidad a las afirmaciones del marido en el sentido de que él y su hija son víctimas de violencia, y se pasan por alto las denuncias de violencia por parte del esposo contra su esposa y su hija. Resulta así patente el androcentrismo en este caso.

Así mismo, es muy clara la existencia de un estereotipo compuesto, pues, a más de la subordinación en la que se encontraba como mujer frente a su pareja, esta situación de vulnerabilidad se veía agudizada por el hecho de ser migrante de Gambia, no hablar el húngaro, depender económicamente de su marido, tener una hija pequeña y no contar con ningún apoyo familiar en Hungría.

No obstante, en ningún momento esta situación de vulnerabilidades múltiple fue tomada en cuenta por los tribunales nacionales, lo cual revela además una insensibilidad de género, en tanto no se tuvo en consideración la desigualdad real en esta pareja, agudizada aún más por la situación de aislamiento en la que vivía esta mujer migrante de origen africano.

En este punto, hemos analizado casos relacionados con violencia contra las mujeres en el ámbito familiar. Acontinuación estudiaremos tres casos relacionados con violencia sexual contra las mujeres.

34. Comunicación No. 31/2011. Isatou Jallow contra Bulgaria, párrafo 8.6. 


\section{VIOLENCIA SEXUAL CONTRA LAS MUJERES}

Dentro de los dictámenes de la CEDAW que se analizan en este estudio, dos se relacionan con violencia sexual perpetrada por personas particulares. Uno de ellos es el de Vertido contra Filipinas. ${ }^{35}$ La autora, quien trabajaba como directora ejecutiva de la Cámara de Comercio e Industria de Davao, afirma que fue víctima de violación por parte del Presidente de dicha cámara, quien luego de 8 años de duración del proceso judicial fue absuelto sobre la base de falsedades y estereotipos de género.

La riqueza de la argumentación de la autora merece ser destacada. Resumiendo, identifica ocho expresiones de tales falsedades y estereotipos que fueron la base para absolver al acusado: ${ }^{36}$

- La víctima de una violación debe intentar escapar a la menor oportunidad. La autora alega que la magistrada no tomó en consideración los testimonios periciales, en los que las especialistas en victimología, traumas por violación y psiquiatría habían explicado que las víctimas exhiben una amplia gama de respuestas de comportamiento cuando son amenazadas con ser violadas, al igual que durante la violación y después de ella.

- La idea de que para ser violada mediante intimidación, la víctima debe ser tímida o atemorizarse fácilmente.

- Para concluir que se ha producido una violación mediante amenaza, debe haber pruebas claras de una amenaza directa. La autora sostiene que, en lugar de evaluar las pruebas teniendo en cuenta el contexto y examinar las circunstancias como un todo, el Tribunal se centró en la falta de existencia objetiva de una pistola. De acuerdo con la jurisprudencia y la doctrina, es la falta de consentimiento, y no el componente de fuerza, lo que se entiende como elemento constitutivo del delito de violación.

- El hecho de que el acusado y la víctima se conozcan "más que de vista" hace que el acto sexual sea consentido. La autora sostiene que es un grave error entender que cualquier relación entre el acusado y la víctima es una prueba válida del consentimiento de la víctima al acto sexual.

- Que se considere problemático que una víctima de violación pueda reaccionar ante la agresión resistiéndose y también atemorizarse hasta someterse por miedo. La autora sostiene el Tribunal impone injustamente a las víctimas de viola-

35. Comunicación No. 18/2008. Karen Tayag Vertido contra Filipinas. Dictamen del Comité de Eliminación de la Discriminación contra la Mujer de 16 de julio de 2010.

36. Ibíd., párrafo 3.5. 
ción un criterio de comportamiento "normal" o "natural” y discrimina a las que no se ajustan a ese criterio.

- La afirmación según la cual la víctima de la violación no puede haberse opuesto a la agresión sexual si el acusado logró eyacular. La autora alega que el hecho de que el acusado eyaculase o no es completamente irrelevante en un juicio por violación, ya que no es un elemento del delito, no prueba que el acto sexual fuese consentido y no niega la resistencia de la víctima.

- Es increíble que un sexagenario sea capaz de perpetrar una violación. La autora sostiene que, si esa falsedad se aplicase a todos los acusados sexagenarios, toda causa en la que una persona alegase haber sido violada por un hombre de edad avanzada culminaría inevitablemente en la absolución del acusado.

- Es fácil formular una acusación de violación, pero es más difícil para el acusado desmentirla. La autora considera que esa presunción coloca injustificable e inmediatamente bajo sospecha a las víctimas de violación.

Es muy relevante tener en cuenta los daños que la autora alega haber sufrido. Tuvo que soportar ocho años de un litigio que fue muy publicitado, ella y su familia tuvieron que mudarse para escapar de su comunidad que se había vuelto en su contra por atreverse a llevar a juicio a un hombre acaudalado e influyente. Fue obligada a dimitir de su cargo de directora ejecutiva de la Cámara de Comercio de la ciudad de Davao poco después de la violación, y su exempleador le dijo que habían contratado a un hombre (que recibiría el doble de su salario) para evitar que se repitiese su caso. Todos estos factores agravaron su trastorno por estrés postraumático que había estado sufriendo como resultado directo de la violación, y el Estado no la protegió ni a ella ni a su familia, sino que al contrarió la re victimizó. ${ }^{37}$

Sin duda, en el dictamen del Comité sobre el caso Vertido contra Filipinas encontramos el mayor desarrollo interpretativo y argumentativo sobre estereotipos de género.

El Estado parte tiene la obligación de adoptar medidas adecuadas para modificar o abolir no solo las leyes y normas vigentes, sino también los usos y prácticas que constituyan discriminación contra la mujer. A este respecto, el Comité pone de relieve que la aplicación de estereotipos afecta el derecho de la mujer a un juicio imparcial y justo, y que el poder judicial debe ejercer cautela para no crear normas inflexibles sobre lo que las mujeres y las niñas deberían ser o lo que deberían haber hecho al encontrarse en una situación de violación basándose únicamente en nociones preconcebidas de lo que define a una víctima de violación o de violencia basada en el género en general. El Comité recuerda además su recomendación general núm. 19 sobre la violencia contra la mujer. [...] “... de conformidad

37. Ibíd., párrafo 3.7. 
con la Convención, la discriminación no se limita a los actos cometidos por los gobiernos o en su nombre" y que "en virtud del derecho internacional y de pactos específicos de derechos humanos, los Estados también pueden ser responsables de actos privados si no adoptan medidas con la diligencia debida para impedir la violación de los derechos o para investigar y castigar los actos de violencia e indemnizar a las víctimas”. ${ }^{38}$

El Comité califica directamente como un prejuicio de género uno de los principios rectores a los que el Tribunal se remitió en su sentencia, y, según el cual, "una acusación de violación puede hacerse con facilidad pero es más difícil para el acusado desmentirla". 39

\section{Así mismo el Comité puso en evidencia que:}

Pese a que la sentencia se refiere a principios como, por ejemplo, que la resistencia física no es un elemento que permita establecer un caso de violación, que las personas reaccionan de formas distintas ante la tensión emocional y que el hecho de que la víctima no intente escapar no significa que no haya habido una violación, así como al hecho de que "en cualquier caso, la ley no dispone que la víctima de una violación deba demostrar que ejerció resistencia”, la decisión muestra que la magistrada no aplicó esos principios al evaluar la credibilidad de la autora en relación con expectativas sobre la forma en que esta debería haber actuado antes de la violación, durante el acto y después de él debido a las circunstancias y a su carácter y personalidad. La sentencia muestra que la magistrada llegó a la conclusión de que la actitud de la autora había sido contradictoria, por haber reaccionado con resistencia en un momento y sumisión en otro, y que la magistrada consideró que esto era un problema. El Comité observa que el Tribunal no aplicó el principio de que "el hecho de que la víctima no intentara escapar no significa que no haya habido una violación" y, al contrario, esperaba determinado comportamiento de la autora por considerar que no era "una mujer tímida a la que se pudiese atemorizar fácilmente”. Está claro que en la evaluación de la credibilidad de la versión de los hechos presentada por la autora habían influido varios estereotipos, puesto que la autora no había mostrado en esta situación el comportamiento esperado de una víctima ideal y racional, o lo que la magistrada consideraba la respuesta racional e ideal de una mujer en una situación de violación $\left[\ldots . .{ }^{40}\right.$

Se identifican claramente en este caso estereotipos sexuales en los que se espera o prescribe cierto tipo de comportamientos como adecuado o apropiado para las mujeres víctimas de violencia sexual. Concretamente el Tribunal nacional exigió una actitud permanente de resistencia, que no se sintiera intimidada dado que no era una mujer tímida y que intentara escapar. El hecho de que la autora no se amoldara a este

38. Ibíd., párrafo 8.4.

39. Ibíd., párrafo 8.5.

40. Comunicación No. 18/2008. Karen Tayag Vertido contra Filipinas, párrafo 8.5. 
“guion esperable de actuación” en la práctica restó credibilidad a su acusación a los ojos del Tribunal nacional.

Un hecho que llama la atención en este caso es que ni en los tribunales nacionales ni en sede internacional se tuviera en cuenta la relación de poder que existía entre el acusado y la víctima, pues, si bien ella ocupaba un alto cargo, él era su superior y ejercía un cargo de mayor influencia y poder que el suyo en el ámbito laboral. Tan es así que, a partir de que ella presenta la denuncia penal, pierde su trabajo y no logra conseguir uno nuevo, se mantiene desempleada siendo ella y su familia repudiadas por su comunidad hasta el punto de verse forzada a mudarse a otra ciudad.

Otra idea estereotipada que el Comité adecuadamente explicita tiene que ver con el prototipo de víctima de una violación que muchas veces excluye de la protección a aquellas mujeres que no se ajustan al mismo.

Aunque, según el precedente legal establecido por el Tribunal Supremo de Filipinas, para probar que no hubo consentimiento no es necesario demostrar que el acusado venciera a la resistencia física de la víctima, el Comité considera que esperar que la autora se resistiera en esa situación refuerza de forma particular el mito de que las mujeres cultas, que saben expresarse bien, decentes y casadas no pueden ser víctimas de violación. A este respecto, el Comité destaca que no debería suponerse, en la ley ni en la práctica, que una mujer da su consentimiento porque no se ha resistido físicamente a la conducta sexual no deseada, independientemente de si el autor del delito utilizó o amenazó con utilizar violencia física. ${ }^{41}$

También el Comité muestra su preocupación por otros estereotipos sobre la sexualidad femenina que sustentan la decisión judicial nacional, y que apoyan más la credibilidad del presunto violador que la de la víctima. Por ejemplo, la conclusión de la magistrada de que es increíble que un sexagenario fuera capaz de llegar hasta la eyaculación cuando la autora estaba resistiéndose al ataque sexual, o el valor que se da al hecho de que la autora y el acusado se conocieran para excluir la existencia de violación. ${ }^{42}$

La relevancia que el tribunal nacional da al hecho de que el acusado tuviera 60 años tiene que ver con un estereotipo de sexo (relacionado con las características físicas de hombres y mujeres). De acuerdo con el razonamiento del Tribunal resultaría que todo hombre de 60 años o más estaría impedido físicamente de cometer una violación. No es claro si esta afirmación se da porque se lo considera débil o limitado en su potencia sexual. En cualquier caso, lo problemático es cómo una creencia generalizada (estereotipo) deja de lado el análisis de la situación concreta y de las características específicas de las personas involucradas en el proceso judicial.

\footnotetext{
41. Ibíd., párrafo 8.5 .

42. Ibíd., párrafo 8.6.
} 
Es muy relevante traer a colación lo que el Comité ha aclarado varias veces, esto es que "la violación constituye una infracción del derecho de las mujeres a la seguridad personal y la integridad física, y que su elemento esencial es la falta de consentimiento". ${ }^{43}$ En este caso el Comité reconoció que la autora sufrió daños y perjuicios morales y sociales, en particular debido a la excesiva duración del proceso judicial, y que se volvió a convertir en víctima a causa de los estereotipos y prejuicios de género en que se basó la sentencia. ${ }^{44}$

El otro caso sobre violencia sexual es el de R.P.B. contra Filipinas.$^{45}$ La autora es una mujer sorda perteneciente a una familia de escasos recursos económicos de Manila, quien afirma que a los diecisiete (17) años de edad fue violada por su vecino, un joven de 19 años, y que los tribunales absolvieron al acusado sobre la base de estereotipos y falsedades de género.

El caso guarda similitud con el de Vertido contra Filipinas, como veremos a continuación. En efecto, el Comité reafirma que la aplicación de estereotipos afecta el derecho de la mujer a un juicio imparcial y justo, y que las autoridades deben evitar crear normas inflexibles basadas en preconcepciones sobre lo que define a una víctima de violación. ${ }^{46}$

El tribunal de primera instancia esperaba de la autora un cierto tipo de comportamiento que una mujer filipina corriente tenía que demostrar en las circunstancias, a saber, recurrir "a toda su fuerza y su valor para frustrar todo intento de profanar su honor y su pureza”. En segundo lugar, el tribunal evaluó la conducta de la autora con arreglo a esta norma y llegó a la conclusión de que "el comportamiento de la autora no era coherente con el de una filipina corriente" y con el "nivel razonable de comportamiento de un ser humano", porque no había tratado de escapar ni de resistir al acusado, en particular haciendo ruido o utilizando la fuerza. El tribunal declaró que "el hecho de que la autora ni siquiera trató de escapar [...] o por lo menos de gritar pidiendo ayuda, a pesar de las oportunidades para hacerlo, pone en tela de juicio su credibilidad y hace que su alegación de falta de consentimiento sea difícil de creer”. El Comité considera que, en sí mismas, las conclusiones revelan la existencia de fuertes estereotipos que se traducen en discriminación basada en el sexo y el género, y un desconocimiento de las circunstancias particulares del caso, como la discapacidad y la edad de la autora. ${ }^{47}$

En la afirmación del tribunal filipino se constata una creencia generalizada respecto al valor que una víctima de violación tiene que proteger "su honor y pureza”,

\footnotetext{
43. Ibíd., párrafo 8.7 .

44. Ibíd., párrafo 8.8 .

45. Comunicación No. 34/2011. R.P.B. contra Filipinas. Dictamen del Comité de Eliminación de la Discriminación contra la Mujer de 21 de febrero de 2014.

46. Ibíd., párrafo 8.8 .

47. Ibíd., párrafo 8.9 .
} 
no se tiene en cuenta su integridad personal, su autonomía y su seguridad. Rezagos del estereotipo de que una mujer que es agredida sexualmente queda mancillada, deshonrada, manchada es el trasfondo de esta frase. Por lo mismo, lo que se espera como actuación de una filipina corriente es resistirse con toda su fuerza a este ataque, estandarizando así la única respuesta o reacción que el tribunal califica como coherente.

En este caso, resulta todavía más compleja esta afirmación por cuanto deja de lado la triple situación de vulnerabilidad de la mujer que es adolescente, con discapacidad auditiva y perteneciente a una familia de escasos recursos económicos. Por lo mismo, se configura un estereotipo compuesto en el que las creencias preconcebidas sobre las niñas sordas operan para dejarlas en un mayor nivel de desprotección. Inclusive, en varias instancias del proceso judicial el Estado no le proporcionó interpretación en lengua de señas ni tuvo en cuenta el mayor riesgo y las múltiples formas de discriminación que sufren las mujeres con discapacidades, tal como lo advierte la Convención sobre los Derechos de las Personas con Discapacidad. ${ }^{48}$

El Comité reitera lo que ya se analizó en el caso Vertido contra Filipinas respecto a que un elemento esencial del delito de violación es la falta de consentimiento, y que dentro de los estereotipos de género y las ideas erróneas aplicadas por el tribunal de primera instancia están la falta de resistencia y el consentimiento de la víctima de violación y el uso de la fuerza y la intimidación por parte del perpetrador. ${ }^{49}$

Finalmente, "el Comité reconoce que la autora ha sufrido daños y perjuicios morales y sociales, en particular por la excesiva duración del proceso judicial, por el hecho de que el tribunal no le brindó la asistencia gratuita de intérpretes en lengua de señas, y por la utilización de falsedades y estereotipos de género y el hecho de no tener en cuenta en la sentencia su situación específica como niña sordomuda". ${ }^{50}$

Vale la pena enfatizar que el uso del término sordomuda es incorrecto pues implica que la persona que sufre una discapacidad auditiva (no puede escuchar), tampoco podría comunicarse, lo cual no es cierto en el caso de las personas sordas, pues se comunican a través de su propio lenguaje (la lengua de señas).

48. Preámbulo, párrafo q) “Las mujeres y las niñas con discapacidad suelen estar expuestas a un riesgo mayor, dentro y fuera del hogar, violencia, lesiones o abuso...”; Art. 6.1. Los Estados Parte reconocen que las mujeres y las niñas con discapacidad están sujetas a múltiples formas de discriminación...”.

49. Comunicación No. 34/2011. R.P.B. contra Filipinas, párrafo 8.10.

50. Ibíd., párrafo 8.11. 
En el caso Abramova contra Belarús, ${ }^{51}$ la autora sostiene haber sido víctima de tortura y tratos inhumanos y degradantes durante su detención administrativa ${ }^{52}$ en un centro en donde todo el personal era masculino. En este caso el Comité estableció la violación del art. 5 a) de la CEDAW referente a estereotipos de género sin mayor desarrollo argumentativo. ${ }^{53}$

En este punto hemos analizado tres casos relacionados con violencia sexual contra mujeres; en el siguiente punto nos enfocaremos en casos de discriminación contra mujeres que afectan derechos económicos, sociales y culturales.

\section{DisCRIMINACIÓN CONTRA LA MUJER EN SUS DERECHOS ECONÓMICOS, SOCIALES Y CULTURALES}

Se han agrupado en este punto tres casos que se relacionan con la discriminación en el reconocimiento y ejercicio del derecho a la salud, al empleo y a la propiedad.

En el caso T.P.F. contra Perú, ${ }^{54}$ la autora afirma que su hija sufrió abuso sexual y que, fruto de ello, quedó embarazada a los 13 años de edad, razón por la cual intentó suicidarse lanzándose de un edificio. Fue atendida en un hospital público, y, dado que su columna sufrió lesiones severas, se fijó fecha para su intervención quirúrgica que fue suspendida cuando los médicos conocieron de su estado de gestación. La autora solicitó que se le realizará un aborto terapéutico conforme con la legislación peruana. Sin embargo, los médicos de este hospital negaron dicha solicitud en dos ocasiones. Su hija tuvo un aborto espontáneo y recién ahí, más de tres meses después de que se decidiera la necesidad de su intervención, fue operada de su columna. Actualmente se encuentra paralizada desde el cuello para abajo y solo ha recuperado parcialmente la movilidad de las manos. Depende de una silla de ruedas para moverse y de terceros para todas sus necesidades.

La autora asevera que "condicionar el acceso a un tratamiento médico oportuno, del que dependía el ejercicio del derecho a la salud, a la vida, y a la vida en condiciones dignas, a completar un embarazo involuntario resultó en un trato discriminatorio que se basó en el estereotipo de dar prioridad a la función reproductiva de L. C. por

51. Comunicación No. 23/2009. Inga Abramova contra Belarús. Dictamen del Comité de Eliminación de la Discriminación contra la Mujer de 25 de julio de 2011.

52. Fue sancionada a 5 días de detención administrativa por vandalismo menor, a saber: colocar lazos azules y pancartas en las calles convocando a la Marcha Europea.

53. Comunicación No. 23/2009. Inga Abramova contra Belarús, párrafo 7.7.

54. Comunicación No. 22/2009. T.P.F. contra Perú. Dictamen del Comité de Eliminación de la Discriminación contra la Mujer de 17 de octubre de 2011. 
encima de su bienestar". ${ }^{55}$ Sostiene que su hija "fue víctima de exclusiones y restricciones en el acceso a los servicios de salud basadas en un estereotipo de género que entiende el ejercicio de la capacidad reproductora de la mujer como un deber en vez de un derecho". ${ }^{56}$

El Comité llegó a la siguiente conclusión:

El Comité considera que, debido a su condición de mujer embarazada, L. C. no tuvo acceso a un procedimiento eficaz y accesible que le permitiese establecer su derecho a los servicios de atención médica que su estado de salud física y mental requería. Estos servicios comprendían tanto la operación de columna como el aborto terapéutico. Ello resulta tanto más grave si se tiene en cuenta que se trataba de una menor, víctima de abusos sexuales. El intento de suicidio demuestra el grado de sufrimiento mental por el que pasó como consecuencia de los abusos. [...] los hechos ponen de manifiesto una violación del artículo 5 de la Convención, ya que la decisión de aplazar la intervención quirúrgica debido al embarazo estuvo influenciada por el estereotipo de que la protección del feto debe prevalecer sobre la salud de la madre. ${ }^{57}$

Efectivamente, este caso muestra con mucha claridad el estereotipo de roles sexuales que prescribe que la mujer en tanto madre debe estar dispuesta a sacrificarse a sí misma por sus hijos/as incluyendo los que están por nacer. Es esa la conducta que la Junta Médica -que negó la interrupción del embarazo- exigió de la niña. Cabe desatacar que el Colegio de Médicos tuvo una opinión diferente en el sentido de que "existían argumentos suficientes, para afirmar que, de continuar el embarazo, la salud física y mental de la niña estaba en grave riesgo por lo que se justificaba el aborto terapéutico". ${ }^{58}$ No obstante, esta opinión no fue tomada en cuenta por el hospital público al que acudió la niña.

En las decisiones de la Junta Médica no se tienen en cuenta otros factores que se intersecan para crear una situación de mayor vulnerabilidad en este caso, como son la edad de la niña, el haber sido víctima de violencia sexual, su estado de depresión extrema que la lleva a intentar suicidarse y su pertenencia a una familia de escasos recursos.

En el caso R.K.B. contra Turquía ${ }^{59}$ la autora afirma haber sido despedida a causa de una discriminación de género, dado que su empleador justificó su despido ante los tribu-

55. Ibíd., párrafo 3.3 .

56. Ibíd., párrafo 7.7.

57. Ibíd., párrafo 8.15 .

58. Ibíd., párrafo 8.14 .

59. Comunicación No. 28/2010. R.K.B. contra Turquía. Dictamen del Comité de Eliminación de la Discriminación contra la Mujer de 24 de febrero de 2012. 
nales porque ella habría dado lugar a rumores de relaciones de índole sexual con personas del sexo opuesto incluido uno de los gerentes de la peluquería en la que laboraba. El tribunal nacional resolvió que la rescisión del contrato había sido injustificada e improcedente y concedió a la autora una indemnización por despido, pero negó que se hubiera infringido el principio de igualdad de trato afirmando que el hecho de que el hombre con quien se decía que había mantenido una relación con la autora, hubiera conservado su empleo no era suficiente para demostrar una discriminación por motivo de género.

El Comité da cuenta de la relación entre estereotipos de género y la discriminación a la mujer en los siguientes términos:

El Comité considera preocupante que en ningún momento la Sala Tercera del Tribunal del Trabajo de Kocaeli reprobara el sesgo sexista y el carácter discriminatorio de los testimonios favorables al empleador. En lugar de rechazar inmediatamente esta defensa del empleador, claramente constitutiva de discriminación por motivos de género y contraria al principio de igualdad de trato, el tribunal examinó las pruebas aducidas por el empleador y sometió a examen únicamente la integridad moral de la autora, que era mujer, y no la de los empleados varones, a saber el Sr. M. A. y el Sr. D. U. (...) El Comité considera que, en el caso que se examina, las actuaciones judiciales se basaron en la percepción estereotipada de la gravedad de que una mujer mantuviera una relación extramatrimonial, y en la consideración de que este tipo de relaciones eran aceptables en el caso de un hombre pero no en el de una mujer, y de que solo las mujeres tenían el deber de "no incurrir ni en el más mínimo atentado contra la moral”. ${ }^{60}$

De acuerdo con la tipología desarrollada por Rebecca Cook y Simone Cusack, se trata de un ejemplo de un estereotipo sexual que se vincula con la interacción sexual, y con lo que se considera apropiado o no para hombres y mujeres. En este caso, y tal como lo destaca el Comité, es completamente aceptable que los hombres tengan relaciones extramatrimoniales, mientras que esta misma conducta resulta absolutamente reprochable en el caso de las mujeres. Como se evidencia, este estereotipo incide de manera directa en la violación del derecho al trabajo de la autora. Este caso es un claro ejemplo de una manifestación de sexismo, como es el doble parámetro que consiste en que una misma conducta y/o una situación idéntica son valoradas o evaluadas con distinta medida para uno y otro sexo, fundamentadas en el deber ser de cada sexo. ${ }^{61}$ Lo más frecuente es que esta evaluación desigual según sea realizada por un hombre o una mujer, generalmente, reproduce un juicio severo para las mujeres y una actitud condescendiente en el caso de los hombres.

60. Ibíd., párrafo 8.7.

61. Facio, "Metodología para el análisis de género del fenómeno legal”, 208-9. 
En el caso E.S. y S.C. contra República Unida de Tanzania ${ }^{62}$ las autoras afirman que, en su calidad de mujeres viudas, han sido víctimas de discriminación de género, ya que se les ha impedido administrar y heredar los bienes tras el fallecimiento de sus maridos, por cuanto las normas sucesorias del derecho consuetudinario son patrilineales, y, por lo mismo, dan prevalencia a los herederos varones sobre las mujeres. Aunque el Tribunal Superior dictaminó que la normativa impugnada era discriminatoria en varios sentidos, sostuvo que era imposible introducir un cambio en la costumbre mediante procedimientos judiciales.

Se resalta que este es el único caso, de los doce que hemos analizado, en el que la discriminación es de jure y de facto, pues es el derecho consuetudinario el que establece esta discriminación que es aplicada en la práctica.

En este caso, el Comité insiste en que "la aplicación de costumbres discriminatorias perpetúa los estereotipos de género y las actitudes discriminatorias sobre las funciones y responsabilidades de la mujer e impide que las mujeres gocen de igual condición en la familia y en la sociedad en general”.

El Comité observa que las cuestiones relacionadas con la sucesión están reguladas por múltiples sistemas jurídicos en el Estado parte y que las autoras se han visto sometidas al derecho consuetudinario sukuma, debido a su origen étnico. El Comité observa también que, aunque su Constitución incluye disposiciones que garantizan la igualdad y la no discriminación, el Estado parte no ha revisado ni adoptado medidas legislativas para eliminar los aspectos discriminatorios restantes de las disposiciones de su derecho consuetudinario codificado en lo que respecta a las viudas. Por consiguiente, las autoras se vieron privadas del derecho a administrar los bienes de sus cónyuges y quedaron excluidas de la herencia de todos los bienes al fallecer aquellos. El Comité considera que el marco jurídico del Estado parte, que trata a las viudas y viudos de manera diferente en lo que respecta al acceso a la propiedad, adquisición, gestión, administración, disfrute y enajenación de los bienes, es discriminatorio $[\ldots] .^{63}$

Aunque el Comité cuestiona los estereotipos de género y las actitudes discriminatorias sobre las funciones y responsabilidades de la mujer no especifica a qué funciones y roles de género estereotipados en la familia se está refiriendo. Entonces, ¿cuáles son los estereotipos que están actuando en esta normativa que es parte del derecho consuetudinario de la República de Tanzania? Innegablemente, se trata de estereotipos de roles sexuales que establecen qué tipo de actividades o funciones son apropia-

62. Comunicación No. 48/2013. E.S. y S.C. contra República Unida de Tanzania. Dictamen del Comité de Eliminación de la Discriminación contra la Mujer de 2 de marzo de 2015.

63. Ibíd., párrafo 7.6. 
das para hombres y cuáles para mujeres. Se refuerza la idea de que son los hombres los llamados a tener propiedades y administrarlas, mientras que las mujeres, en este caso las viudas, son despojadas de todo derecho de propiedad y administración, quedando supeditadas a un "tutelaje-protección” por parte de hombres (sus hijos varones, su suegro o su cuñado). Esta distribución sexual de funciones asume la capacidad de los hombres para el manejo de asuntos económicos, mientras que al mismo tiempo niega esa capacidad en el caso de las mujeres.

Obviamente, estos estereotipos de género inciden directamente en la discriminación a la mujer en el ejercicio de varios derechos (la igualdad ante la ley, el reconocimiento de su igual capacidad jurídica, la igualdad en las relaciones familiares y matrimoniales, particularmente el derecho a la propiedad, administración, goce y disposición de bienes).

\section{CONCLUSIONES}

Los estereotipos de género operan muchas veces de manera inconsciente y reproducen formas de subordinación, entre ellas discriminación y violencia, que afectan generalmente a las mujeres. Por lo mismo, tomar conciencia de la existencia de los estereotipos de género y desvelar el vínculo entre estos y las violaciones de derechos humanos es una tarea necesaria.

Resulta aún más problemático cuando los estereotipos de género asociados con la subordinación de las mujeres son reproducidos y reforzados a través de la normativa, las políticas públicas o las prácticas estatales porque en tales casos se revisten de un carácter de legitimidad muchas veces asociado con la ley y la autoridad.

La CEDAW es el primer tratado internacional de derechos humanos de las mujeres que en su art. 5 a) incorpora la obligación de los estados de modificar los patrones socioculturales de conducta de hombres y mujeres con el fin de eliminar los prejuicios y las prácticas consuetudinarias basados en ideas de inferioridad y superioridad entre los sexos, y de funciones estereotipadas entre hombres y mujeres.

Dentro de la jurisprudencia del Comité de Eliminación de la Discriminación contra la Mujer desde el 2005 hasta el 2015 se encuentran doce comunicaciones individuales en las que se alega y/o se declara la violación del art. 5 a) de la CEDAW vinculado con los estereotipos de género.

Del análisis de estas doce comunicaciones se concluye que el tratamiento que el Comité brinda a los estereotipos de género presenta variaciones en cuanto a su desarrollo argumentativo e interpretativo. Sin duda, merece una mención especial el dictamen sobre el caso Vertido contra Filipinas, que se destaca por presentar el mayor desarrollo argumentativo o interpretativo del Comité sobre estereotipos de género. 
Consideramos que contribuye a ello, la comunicación presentada por la autora que aporta muchos elementos para la comprensión y deconstrucción de estereotipos de género en casos de violencia sexual.

En contraste, en los dictámenes de los casos Descendiente de Fatma Yildirin contra Austria, Descendientes de Sahide Guekce contra Austria, y Abramova contra Belarús se constata una falta de motivación tanto para negar la violación del art. 5 a) como para declararla. Se da un tratamiento muy escueto, casi que una mera mención.

A continuación, se sintetizan los aportes y los límites encontrados en aquellos dictámenes que en mayor o menor medida motivan su decisión de declarar la violación del art. 5 a) de la CEDAW. Se identifican como aportes en el desarrollo jurisprudencial del Comité de la CEDAW sobre estereotipos de género que deben ser tenidos en cuenta como estándares los siguientes:

- Los estereotipos afectan el derecho de la mujer a un proceso judicial imparcial y justo y que el poder judicial no puede aplicar ideas preconcebidas e inflexibles sobre lo que constituye violencia doméstica o lo que define a una víctima de violación o de violencia basadas en el género o el comportamiento esperado como una respuesta racional e ideal de una mujer en una situación de violación.

- Las actitudes tradicionales en que se considera a las mujeres subordinadas a los hombres contribuyen a la violencia en el hogar.

- El cuestionamiento frontal a nociones preconcebidas de que la violencia doméstica es en gran medida un asunto privado que incumbe a una esfera en que, en principio, el Estado no debe ejercer control.

- Los derechos del agresor (a la libertad personal) no pueden estar por encima de los derechos humanos de las mujeres a la vida y a la integridad personal en aquellos casos en que la privación de la libertad resulta necesaria para proteger a la mujer en contextos de violencia en el ámbito familiar y riesgo evidentes. ${ }^{64}$

- Los Estados parte están obligados al momento de adoptar decisiones sobre custodia y derecho de visitas a considerar el contexto de violencia doméstica a la luz del interés superior de los niños y niñas para ir más allá de una igualdad formal que al desconocer el contexto los deja en desprotección.

- En los casos de violencia sexual, se debe evitar brindar una mayor credibilidad al presunto violador y restarle a la de la víctima sobre la base de estereotipos respecto del comportamiento "normal” o "racional” que debería tener una víctima de violencia sexual. La violación constituye una infracción del

64. Habría sido importante que el Comité desarrolle de manera más específica criterios o parámetros para determinar la necesidad de las medidas privativas de la libertad en tales casos. 
derecho de las mujeres a la seguridad personal y la integridad y su elemento esencial es la falta de consentimiento. No debería suponerse ni en la ley ni en la práctica, que una mujer da su consentimiento porque no se ha resistido físicamente a la conducta sexual no deseada, independiente de si el autor del delito utilizó o amenazó con utilizar violencia física o porque conocía, anteriormente, al acusado.

- La calificación directa como prejuicio de género a la afirmación de un tribunal filipino de que "una acusación de violación puede hacerse con facilidad, pero es más difícil para el acusado desmentirla".

- La aplicación injustificada de estereotipos de género negativos es causa fundamental y consecuencia de la discriminación contra la mujer y se perpetúan a través de varios medios e instituciones como leyes y sistemas judiciales y que pueden ser reforzados tanto por agentes estatales como por agentes privados.

- El aplicar percepciones estereotipadas sobre la gravedad de una conducta de carácter sexual en el caso de mujeres, pero no en el de hombres, constituye una clara discriminación contra la mujer.

- El cuestionamiento al estereotipo de que la protección del feto debe prevalecer sobre la salud de la madre.

- El que el Estado también es responsable por violaciones a los derechos reconocidos en la CEDAW que han sido violentados en el derecho consuetudinario en los Estados con múltiples sistemas jurídicos.

Se identifican como límites en el desarrollo jurisprudencial del Comité de la CEDAW sobre estereotipos de género los siguientes:

- Varios casos de violencia en el ámbito familiar presentan evidencias de la devaluación de la palabra y necesidades de las mujeres víctimas de violencia en las instancias judiciales. No obstante, el Comité no realiza el vínculo de estos hechos con la existencia de estereotipos de género que reproducen esta falta de credibilidad y que colocan las necesidades de las mujeres en un segundo plano frente a las de los hombres y que por lo mismo afectan el derecho de la mujer a un juicio imparcial.

- En el caso E.S. y S.C. contra Tanzania, el Comité menciona de manera puntual que existen un estereotipo de género y actitudes discriminatorias sobre funciones y responsabilidades de la mujer, pero no explica en qué consisten estos, cómo operan en concreto y su incidencia en la violencia y la discriminación contra la mujer.

- El Comité dejó de lado, en el caso González contra España, la identificación de un generalizado estereotipo sexual que refuerza la idea de que la mujer es propiedad de su pareja aun cuando estén separados y según la cual el hombre 
tendría derecho a conocer, controlar y/o cuestionar su vida afectiva, aun utilizando a su hija como "informante" de la vida afectiva de su madre a través de las visitas parentales.

- El Comité soslaya el vínculo entre estereotipos sexuales y relaciones de poder jerarquizadas, por ejemplo, en el ámbito laboral. No encontramos un análisis al respecto en los casos Vertido contra Filipinas ni en R.K.B. contra Turquía en los que esta perspectiva habría sido muy pertinente.

- El Comité no profundiza en la manera como operan estereotipos compuestos en los que varias condiciones se interrelacionan para incidir en la violencia y la discriminación contra la mujer. Varios casos analizados presentan la intersección de diversas condiciones en las que, a más del género, la edad, la discapacidad, la condición económica, la nacionalidad o procedencia, la etnia, el estado civil, entre otras, agudizan la situación de desprotección de las víctimas de manera muy particular. El Comité las menciona, pero no desarrolla un análisis interseccional.

- Dado que la CEDAW es un tratado internacional del Sistema de Naciones Unidas, las comunicaciones que recibe con la alegación de violaciones al art. 5 a) provienen de diversos países con su propio contexto cultural. Ciertamente, los estereotipos son de carácter cultural, no obstante, esta diversidad cultural no es tratada en ninguno de los dictámenes que se ha analizado.

Para concluir, cabe insistir en la importancia de tomar conciencia de un elemento problemático que está en la raíz de diversas expresiones de violencia y discriminación contra las mujeres (en este caso los estereotipos de género). Este trabajo pretende contribuir a esa toma de conciencia, pues darse cuenta es indispensable para avanzar en cualquier proceso de transformación.

\section{BIBLIOGRAFÍA}

Bazzano, M. Micaela. “Estereotipos de género en la niñez. Una mirada desde los derechos humanos”. En Ana María Goetschel, coord., Perspectivas de la educación en América Latina. Quito: FLACSO/Ministerio de Cultura del Ecuador, 2009.

Cook, Rebecca, y Simone Cusack. Estereotipos de género. Perspectivas legales transnacionales. Bogotá: Profamilia, 2010.

Facio, Alda. "La Carta Magna de todas las mujeres”. En Ramiro Ávila, Judith Salgado y Lola Valladares, comp., El género en el derecho. Ensayos críticos. Quito: Ministerio de Justicia y Derechos Humanos/UNIFEM/Alto Comisionado de las Naciones Unidas para los Derechos Humanos, 2009.

---. “Metodología para el análisis de género del fenómeno legal”. En Ramiro Ávila, Judith Salgado y Lola Valladares, comp., El género en el derecho. Ensayos críticos. Quito: Minis- 
terio de Justicia y Derechos Humanos/UNIFEM/Alto Comisionado de las Naciones Unidas para los Derechos Humanos, 2009.

Pateman, Carole. “Críticas feministas a la dicotomía público/privado”. En Ramiro Ávila, Judith Salgado y Lola Valladares, comp., El género en el derecho. Ensayos críticos. Quito: Ministerio de Justicia y Derechos Humanos/UNIFEM/Alto Comisionado de las Naciones Unidas para los Derechos Humanos, 2009.

Salgado Álvarez, Judith. Manual de formación en género y derechos humanos. Quito: Universidad Andina Simón Bolívar/Corporación Editora Nacional, 2013.

\section{JURISPRUDENCIA INTERNACIONAL}

Comité de Eliminación de la Discriminación contra la Mujer.

Comunicación No. 48/2013. E.S. y S.C. contra República Unida de Tanzania, 2 de marzo de 2015.

No. 47/2012. Ángela González Carreño contra España, 16 de julio de 2014.

Comunicación No. 34/2011. R.P.B. contra Filipinas, 21 de febrero de 2014.

Comunicación No. 31/2011. Isatou Jallow contra Bulgaria, 23 de julio de 2012.

Comunicación No. 28/2010. R.K.B. contra Turquía, 24 de febrero de 2012.

Comunicación No. 22/2009. T.P.F. contra Perú, 17 de octubre de 2011.

Comunicación No. 23/2009. Inga Abramova contra Belarús, 25 de julio de 2011.

Comunicación No. 20/2008. Violeta Komova contra Bulgaria, 25 de julio de 2011.

Comunicación No. 18/2008. Karen Tayag Vertido contra Filipinas, 16 de julio de 2010.

Comunicación No. 6/2005. Hijos de Fatma Yildirim contra Austria, 6 de agosto de 2006.

Comunicación No. 5/2005. Descendientes de Sahide Goekce contra Austria, 6 de agosto de 2006.

Comunicación No. 2/2003, A.T. contra Hungría, 26 de enero de 2005.

\section{Normativa INTERNACIONAL}

ONU. Convención sobre la Eliminación de todas las Formas de Discriminación contra la Mujer (1981).

---. Convención sobre los Derechos de las Personas con Discapacidad (2007).

---. Protocolo Facultativo de la Convención sobre la Eliminación de todas las Formas de Discriminación contra la Mujer (2000). 